\title{
Preparation and characterization of RGD-immobilized chitosan scaffolds
}

\author{
Ming-Hua Ho ${ }^{a}$, Da-Ming Wang ${ }^{\mathrm{a}}$, Hsyue-Jen Hsieh ${ }^{\mathrm{a}}$, Hwa-Chang Liu ${ }^{\mathrm{b}}$, Tzu-Yang Hsien ${ }^{\mathrm{c}}$, \\ Juin-Yih Lai ${ }^{\mathrm{d}}$, Lein-Tuan Hou, ${ }^{\mathrm{e}, *}$ \\ ${ }^{a}$ Department of Chemical Engineering, National Taiwan University, Taipei, Taiwan \\ ${ }^{\mathrm{b}}$ Institute of biomedical engineering, National Taiwan University, Taipei, Taiwan \\ ${ }^{\mathrm{c}}$ General Education Center, Chung Kuo Institute of Technology, Taipei, Taiwan \\ ${ }^{\mathrm{d}} R \& D$ Center of Membrane Technology and Department of Chemical Engineering, Chungli, Taiwan \\ ${ }^{\mathrm{e}}$ Graduate Institute of Clinical Dentistry, School of Dentistry, National Taiwan University and Department of Periodontology, \\ National Taiwan University Hospital, Taipei, Taiwan
}

Received 21 May 2004; accepted 31 August 2004

Available online 14 October 2004

\begin{abstract}
Chitosan scaffolds were modified with RGDS (Arg-Gly-Asp-Ser) in the present work via an imide-bond forming reaction between amino groups in chitosan and carboxyl groups in peptides. Successful immobilization was verified with FTIR spectroscopy, and the immobilized amount was determined to be on the order of $10^{-12} \mathrm{~mol} / \mathrm{cm}^{2}$ through analysis of the immobilized amino acids. Results of experiments of cell culture with rat osteosarcoma (ROS) cells demonstrated that RGDS immobilization could enhance the attachment of ROS cells onto the chitosan, resulting in higher cell density attached to the RGDS-modified scaffold than to the unmodified scaffold. It should be noted that only RGDS, but not other peptide such as RGES, is effective in enhancing cell attachment and possible proliferation. Experiments of in vitro mineralization indicated that there were more cells on the RGDSmodified scaffold than on the unmodified scaffold, which tended to form bone-like tissues. The results presented in this work suggest that immobilization of RGDS can make chitosan scaffolds more compatible for the culture of osteoblast-like cells and the regeneration of bone-like tissues.
\end{abstract}

(C) 2004 Elsevier Ltd. All rights reserved.

Keywords: Chitosan; Scaffold; RGD; Tissue engineering; Bone regeneration; Biocompatibility

\section{Introduction}

Tissue engineering, a technique for generating new tissues from cultured cells, is now being considered as a potential alternative to organ or tissue transplantation $[1,2]$. One of the key research areas in tissue engineering is the development of techniques to fabricate biocompatible scaffolds, which play an important role in transforming cultured cells into new tissues $[1,3-6]$. In

\footnotetext{
${ }^{*}$ Corresponding author. Department of Periodontology, College of Medicine, National Taiwan University, 1, Chang-Te Street, Taipei 100, Taiwan. Tel.: +886223123456; fax: +886223831346.

E-mail address: 1thou@ha.mc.ntu.edu.tw (L.-T. Hou).
}

such an area, a lot research efforts have been devoted to control the material's chemistry for promotion of highly specific binding interactions between materials and cells, generally involving enrichment of the material surface to promote cell adhesion with extracellular matrix (ECM) components or their functional domains [7-9].

Many studies have attempted to immobilize specific sequences that can promote cell adhesion. RGD (Arg-Gly-Asp) isolated from adhesive proteins is the most widely used one [7-10]. Most researches about immobilization of RGD on biomaterials were carried out in two-dimensional environment (flat surface) [10-15], which cannot reflect the actual environment for cell growth and differentiation [1-3]. Therefore, 
experiments of immobilization of RGD on scaffolds with a three-dimensional structure should be performed to adequately evaluate the effect of RGD immobilization. Researches in this regard have recently attracted much attention [16-20].

The major aim of the present study is to improve the biocompatibility of porous chitosan scaffolds with immobilization of the RGD sequence. Chitosan, a polysaccharide, is an attractive biomaterial for preparation of scaffolds, especially for bone regeneration [21-24]. Immobilization of RGD on chitosan to enhance its biocompatibility was recently carried out on twodimensional chitosan films $[19,25]$. However, conjugation of RGD to chitosan scaffolds with a threedimensional structure has not yet been described. In the present work, immobilization of RGD in chitosan scaffolds was performed with the help of carbodiimide and hydroxysucccinimide. The formation of covalent bonds was confirmed with IR spectroscopy, and the concentration of immobilized RGD was quantified by analyzing the amount of immobilized amino acids. In addition, cell culture experiments were carried out to evaluate the effect of RGD immobilization on the attachment and growth of osteoblast-like cell.

\section{Materials and methods}

\subsection{Materials}

Chitosan used in the present work was purchased from Sigma with a deacetyl degree of $85 \%$. Acetic acid, ethanol, $N, N$-dimethyl formide (DMF), 1-ethyl-3-dimethylaminopropyl carbodiimide (EDC), hydroxysuccinimide (NHS), sodium hydroxide $(\mathrm{NaOH})$, RGDS (Arg-Gly-Asp-Ser), and RGES (Arg-Gly-Glu-Ser), glutaraldehyde were all purchased from Sigma. All solvents are of analytical grade, and the purities of RGDS and RGES are higher than 95\%. For cell culture, $\alpha$-minimum essential medium ( $\alpha$ MEM), sodium $\beta$-glycerophosphate, ascorbic acid, and dexamethasone were purchased from Sigma, and fetal bovine serum (FBS), penicillin-streptomycin-amphotercin, trypsinEDTA solution from GIBCO BRL.

\subsection{Preparation of chitosan films and scaffolds}

Chitosan powder was dissolved in an acetic acid aqueous solution (1 M) to form a $2 \mathrm{wt} \%$ polymer solution. The solution was used to prepare chitosan films and scaffolds. To prepare dense films, the solution was coated onto a petri dish and then dried at $50^{\circ} \mathrm{C}$. The film for cell attachment was circular with a diameter of $6 \mathrm{~cm}$. After the drying stage, the coated film was immersed in a $\mathrm{NaOH}$ aqueous solution $(2 \mathrm{~N})$ to neutralize the remaining acetic acid. Porous chitosan scaffolds were prepared with the so-called freezegelation method, with details described in our previous work [26]. The $2 \mathrm{wt} \%$ chitosan solution was placed in a glass petri dish and frozen at $-20{ }^{\circ} \mathrm{C}$. The frozen chitosan solution was immersed in a $\mathrm{NaOH} /$ ethanol aqueous solution $(40 \mathrm{~g} \mathrm{NaOH}$ powder in $1000 \mathrm{ml}$ $50 \mathrm{vol} \%$ ethanol aqueous solution; the molarity of $\mathrm{NaOH}$ was $1 \mathrm{~m}$ and the $\mathrm{pH}$ value was 12.8 ) at $-20^{\circ} \mathrm{C}$ to allow the adjustment of $\mathrm{pH}$ and the gelation of chitosan. The gelled solution was dried at room temperature to remove the contained liquid. Porous chitosan scaffolds were thus obtained. The size of scaffolds used for cell culture was $5 \mathrm{~mm}$ in length and width, and $2 \mathrm{~mm}$ in height.

\subsection{Peptide immobilization}

Carbodiimide was used to immobilize the RGDS and RGES on chitosan. The protocol was similar to that reported in previous studies of the immobilization of peptides on an amino-phase substrate [27-29]. Peptide $(0.2 \mathrm{~mm}$ in DMF) was mixed with EDC $(2.5 \mathrm{mg} / \mathrm{ml}$ in DMF) and NHS in a 25:25:1 v/v/v ratio. The prepared chitosan scaffolds or films were immersed in the peptide solution at $4{ }^{\circ} \mathrm{C}$ for $72 \mathrm{~h}$ to assure that the immobilization reaction was complete.

\subsection{SEM analysis}

For analysis with scanning electron microscopy (SEM), a gold layer was coated on the specimen surface. Morphologies of specimens were then examined by using a JEOL (JSM-6300, Japan) scanning electron microscope.

\subsection{FTIR-ATR spectroscopy}

Fourier transform infrared spectrometer-attenuated total reflectance (FTIR-ATR) spectra for the unmodified, RGDS-modified, and RGES-modified chitosan scaffolds were obtained with a Perkin-Elmer Spectrum One IR spectrometer (USA).

\subsection{Amino acid analysis}

Samples $(0.05 \mathrm{~g})$ of unmodified, RGDS-modified, and RGES-modified chitosan scaffolds were, respectively, mixed with $3 \mathrm{ml}$ of a $6 \mathrm{~N} \mathrm{HCl}$ aqueous solution to hydrolyze the attached amino acids. The mixtures were kept at $110^{\circ} \mathrm{C}$ for $24 \mathrm{~h}$ and then dried in the oven at $70^{\circ} \mathrm{C}$ for 4-5 days. The hydrolyzed samples were analyzed with an amino acid analyzer (Beckman 6300, USA).

\subsection{Cell attachment on chitosan films}

Cells used for culture experiments were ROS 17/2.8 cells, originally isolated from a rat osteosarcoma. The 
ROS cells possess a typical osteoblastic phenotype and responses similar to those of normal bone cells to hormone stimulation [30,31], and are extensively used in researches about the interaction between bone cells and materials [32,33]. The cells were cultured in $\alpha$ MEM, supplemented with $10 \%$ FBS and $100 \mathrm{U} / \mathrm{ml}$ penicillinstreptomycin-amphotericin, at $37{ }^{\circ} \mathrm{C}$ in $5 \% \mathrm{CO}_{2}$. ROS cells suspended in culture medium $\left(5 \times 10^{4}\right.$ cells $\left./ \mathrm{ml}\right)$ were added to the dishes previously coated with unmodified or modified circular chitosan films with a diameter of $6 \mathrm{~cm}$. After incubation for a certain period of time $(0-10 \mathrm{~h})$, the dish was washed with PBS buffer to remove the unattached cells, and the number of the attached cells was then counted under a microscope (model IX70, Olympus, Japan).

\subsection{Cell culture with chitosan scaffolds}

Modified and unmodified scaffolds were first fixed on culture dishes (Corning, USA) with silicone gel. The scaffold was first placed in the dishes and two or three spots of silicone gel were then applied around the scaffold. A coverslip was placed on the top of the scaffold and adjacent silicone gel spots. Silicone gel was used to glue together the coverslip and the culture dish. ROS cells suspended in the culture medium $\left(5 \times 10^{4}\right.$ cells $\left./ \mathrm{ml}\right)$ were then added to the dishes to allow the ingrowth of cells onto the scaffolds which were $5 \mathrm{~mm}$ in length and width and $2 \mathrm{~mm}$ in height. The constituents in the medium were described in follows, and the medium was changed every 2 days. After incubation for various periods ( 1 and 2 weeks), cells on the scaffolds were harvested for analysis. For SEM analysis, scaffolds with ROS cells were fixed with a $2 \mathrm{wt} \%$ glutaraldehyde solution and dehydrated in ethanol aqueous solutions. Drying with supercritical $\mathrm{CO}_{2}$ was performed to prevent deformation of the cells attached to the scaffolds.

\subsection{Determination of the number of cells attached to scaffolds}

Scaffolds with cultured cells, maintained in culture for 1-4 weeks, were washed with PBS 3 times to remove unattached cells. The washed scaffolds were then immersed in a trypsin-EDTA aqueous solution $(0.05 \%$ $\mathrm{w} / \mathrm{v}$ trypsin and $0.02 \% \mathrm{w} / \mathrm{v}$ EDTA) and incubated at $37^{\circ} \mathrm{C}$ for $10 \mathrm{~min}$ to depart the attached cells. The number of detached cells for each culture period was determined with a hemacytometer.

\subsection{In vitro mineralization}

The mineralization performed according to reported procedures by Hou et al. [34]. In the mineralization stage, the culture medium was replaced with serum-free $\alpha$-MEM medium containing $10 \mathrm{~mm}$ sodium $\beta$-glycero- phosphate, $50 \mu \mathrm{g} / \mathrm{ml}$ ascorbic acid, and $10^{-7} \mathrm{M}$ dexamethasone. Cell culture in scaffolds was maintained for 4-14 days and then subjected to von Kossa staining and determination of $\mathrm{Ca}$ content. Except for the culture medium, the conditions of cell culture were the same as those described in the previous section on cell culture.

\subsection{Histochemical staining: von Kossa staining}

The scaffolds with suspected mineralized cells were stained with a silver nitrate solution and counterstained with Nuclear Fast Red solution [35]. The stained samples were then examined with microscopy (model IX70, Olympus, Japan).

\subsection{2. $E S C A$}

The ratio of $\mathrm{C}$ and $\mathrm{Ca}$ contained in the chitosan scaffolds with mineralized ROS cells (cultured for 2 weeks) were determined by electron spectroscopy for chemical analysis (ESCA; VG Microtech, MT-500, UK). Scaffolds were fixed and dehydrated using the same procedure as those for SEM specimens.

\section{Results and discussion}

\subsection{Fabrication of porous scaffolds}

The porous chitosan scaffolds used in this study were prepared by the so-called freeze-gelation process [26]. In this process, the chitosan solution was frozen to generate phase separation, which results in a porous structure. To prevent destruction of porous structure during the solvent-removal stage, the structure contained in the frozen solution is first fixed by adjustment of the solvent $\mathrm{pH}$ to allow the gelation of chitosan. The gelation process was carried below the freezing point of the polymer solution. After gelation, the contained solvent was removed by vacuum drying at room temperature. The structure of the obtained chitosan scaffolds is shown in Fig. 1a.

\subsection{Peptide immobilization on chitosan}

In the present work, the RGDS sequence was immobilized on chitosan by formation of imide bonds between amino groups on the chitosan and carboxyl groups on the peptides [36-38]. Carbodiimide (EDC) and NHS were involved in this reaction, forming intermediate reactants that led to the formation of imide bonds.

The IR spectra shown in Fig. 2 verify that RGDS and RGES were successfully grafted onto the chitosan. Lines 1 and 2 in Fig. 2 are the IR spectra of the unmodified and RGDS-modified chitosan scaffolds, respectively. 


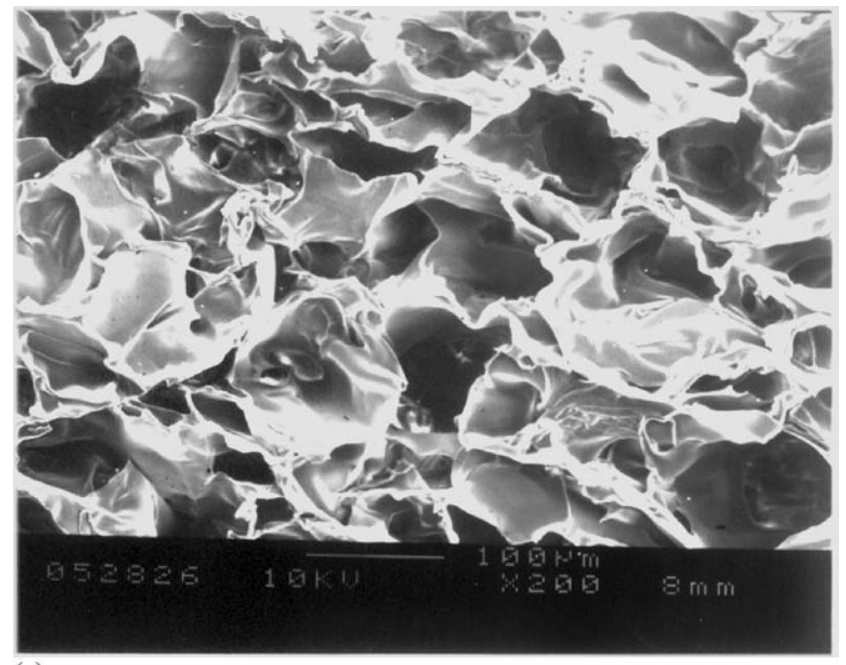

(a)

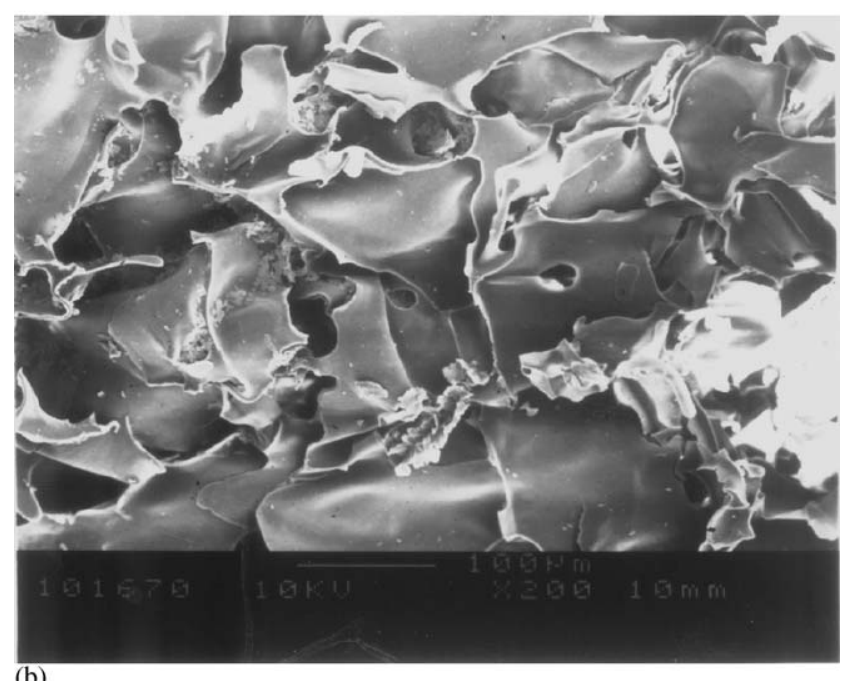

(b)

Fig. 1. Morphology of the chitosan scaffold prepared by the freezegelation method (SEM, $\times 200$ ). (a) Before RGDS immobilization, (b) after RGDS immobilization.

For the unmodified chitosan scaffold (line 1), a peak can be seen clearly at $1542 \mathrm{~cm}^{-1}$, corresponding to the primary $\mathrm{N}-\mathrm{H}$ bending region $\left(1500-1550 \mathrm{~cm}^{-1}\right)$ [39]. For the RGDS-modified scaffold, the peak at $1542 \mathrm{~cm}^{-1}$ disappears, indicating that, molecules have been grafted at the primary amino group of chitosan. Similar results can also be observed for the RGES-modified chitosan, as indicated by line 3 in Fig. 2. The results presented in Fig. 2 provide evidence supporting RGDS and RGES successfully being immobilized onto chitosan by the procedure discussed in Section 2.3.

Quantitative analysis of the concentration of the grafted amount of RGDS (or RGES) on chitosan was also performed by analyzing the concentration of the amino acids. There were four different immobilized amino acids (R, G, D, and S, or R, G, E, and S). For

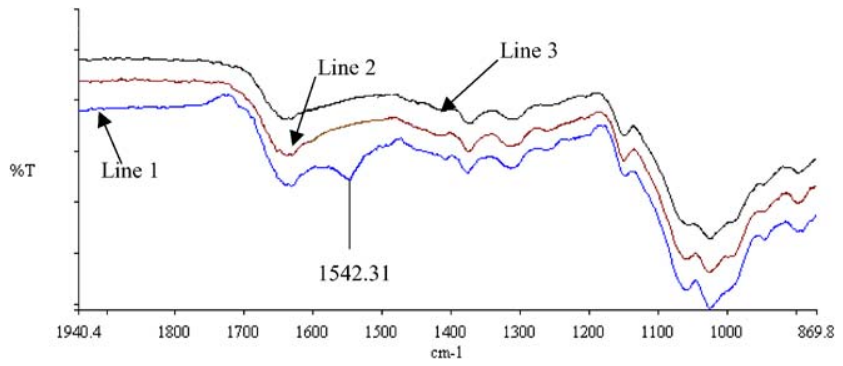

Fig. 2. IR spectra of unmodified, RGDS-modified and RGESmodified chitosan scaffolds. Line 1: unmodified; line 2: RGDSmodified; line 3: RGES-modified chitosan scaffolds.

this analysis, they were stripped from the scaffolds, and their concentrations in the stripping solution were determined using an amino acid analyzer. The concentrations of the four amino acids were roughly the same, and their smallest value was taken to be the peptide concentration. With the volume of the peptide stripping solution, the corresponding peptide concentration, and the mass of the chitosan scaffold, the amount of the immobilized peptide per unit mass of scaffold was determined, and the results are shown in Table 1 . Further calculations can be made by assuming that all pores are spherical. Using this assumption, the porosity of the scaffold, and the density of the chitosan, the surface area per unit mass of the scaffolds can be calculated. Thus, the amount of immobilized peptide per unit surface area was calculated, and the results are also shown in Table 1. The immobilized peptide concentration was on the order of $10^{-12} \mathrm{~mol} \mathrm{~cm}^{-2}$. It has been reported that a peptide (RGD) density of $1 \times 10^{-12} \mathrm{~mol} \mathrm{~cm}^{-2}$ was sufficient to support the adhesion and spreading of fibroblast cells, clustering of integrin receptors, and organization of actin stress fibers [40,41]. Results in Table 1 indicate that the surface concentration of the immobilized RGDS was on the same order as the effective peptide concentration. Hence, the immobilized amount should be high enough to ensure the effect of RGD on cell attachment.

The effect of the immobilization process on the morphology of scaffolds was also investigated. Shown in Figs. 1a and $b$ are the structures of a chitosan scaffold before and after the immobilization process. By comparing Figs. 1a and b, it can clearly be seen that the scaffold remained its original structure after the immobilization process.

\subsection{Effect of RGD immobilization on cell culture}

It has been reported [7-12] that the RGD sequence can promote attachment of cells because it can be recognized by the adhesion receptors on the cell membrane. Thus, the affinity between cells and materials should be improved with the immobilization of 
Table 1

Amounts of immobilized peptides per unit mass of scaffold and per unit surface area of scaffold for RGDS and RGES-modified chitosan scaffolds

\begin{tabular}{lll}
\hline & Chitosan-RGDS & Chitosan-RGES \\
\hline Per unit mass of scaffold (mol RGDS or RGES/g) & $1.1 \times 10^{-8}$ & $3.9 \times 10^{-8}$ \\
Per unit surface area of scaffold (mol RGDS or RGES $/ \mathrm{cm}^{2}$ ) & $8.1 \times 10^{-12}$ & $2.9 \times 10^{-11}$ \\
\hline
\end{tabular}

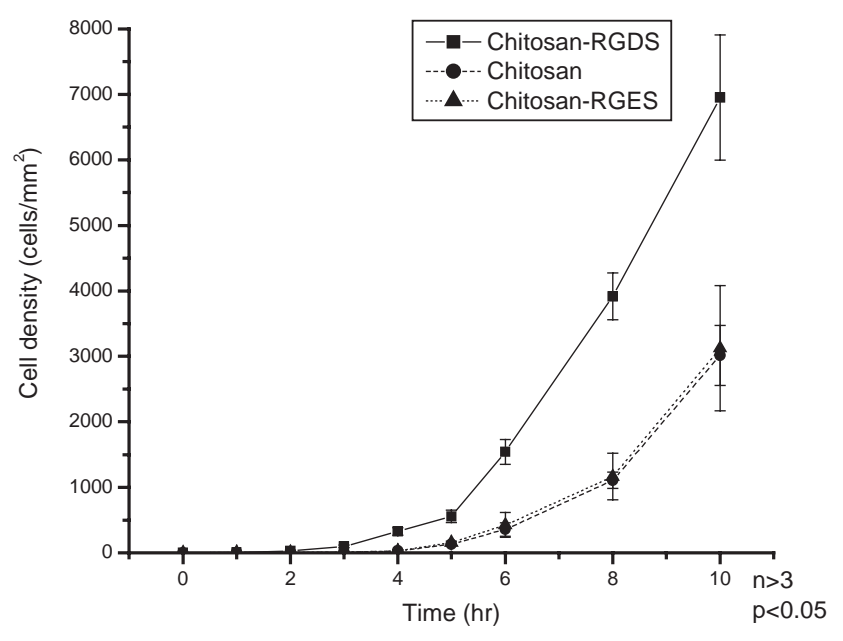

Fig. 3. Cell attachment densities on unmodified, RGDS-modified, and RGES-modified chitosan films.

RGD, which can mimic the natural extracellular matrix. To determine if the initial attachment of ROS cells on chitosan film could be improved by immobilization of RGDS, the number of attached ROS cells at early period after plating (within $10 \mathrm{~h}$ ) on unmodified and RGDS-modified chitosan films was measured, and the results are shown in Fig. 3. Obviously, the ROS cells attached much faster and in greater numbers to the RGDS-modified chitosan film than to the unmodified film. It can also be seen from Fig. 3 that such an effect was strongly related to the peptide used. When the surface was modified with RGES instead of RGDS, the enhancement on cell attachment was not observed. The results support ROS cells being able to recognize the immobilized RGDS sequence, thus attaching faster onto the modified chitosan film.

The culture of ROS cells on RGDS-modified and unmodified chitosan scaffolds was also carried out. SEM micrographs of cultured cells on scaffolds are shown in Figs. 4 and 5. Shown in Figs. 4a and b are ROS cells cultured on RGDS-modified scaffolds for 2 weeks. The fibrils of the ROS cells can clearly be seen, indicating that the cells attached well to the scaffold. In Fig. 5, the SEM micrographs of cells on unmodified and modified scaffolds are presented. It can be seen that, after 1 week of culture, more cells can be found on the RGDS-modified scaffold (Fig. 5c) than on the unmodified (Fig. 5a) and RGES-modified scaffolds (Fig. 5e). Similar results were observed with 2 weeks of culture
(Figs. 5b, d, and f). Obviously, with the same culture time, more cells were observed on the RGDS-modified scaffold, compared to the unmodified and RGESmodified scaffolds.

The number of the ROS cells attached to the scaffolds at different culture times was determined using the method discussed in Section 2.9. The results are depicted in Fig. 6. When the chitosan scaffold was modified with RGDS, with the same culture times, the cell density attached to the modified scaffold was significantly higher than that attached to the unmodified scaffold, which can clearly be seen in Fig. 6. On the other hand, when the scaffold was modified with RGES, cell numbers attached to both the modified and unmodified scaffolds were roughly the same. The results suggest that cells can recognize the difference between RGDS and RGES, and that RGDS, not RGES, is the effective peptide for enhancing cell attachment.

According to the data shown in Fig. 6, the effect of RGDS can clearly be seen after 1 week of culture. After 4 weeks of culture, the cell number attached to the RGDS-modified scaffold seemed to reach a plateau, indicating that the space in the scaffold was almost completely occupied by cells. On the other hand, for scaffolds without modification or modified with RGES, the plateau had not yet been reached by 4 weeks of culture.

On the basis of the above discussion, it is now known that RGDS immobilization can promote the attachment of ROS cells onto the material, as evidenced by the results shown in Fig. 3. The fast attachment of cells resulted in higher cell density attached to the scaffold in the initial culture period. Because of the higher initial density of attached cells, RGDS-modified scaffolds possessed higher cell density than unmodified scaffolds, and thus reached the plateau faster, as shown in Fig. 6. During the first 2 weeks of culture, the effect of RGDS modification could easily be identified. However, because of space limitations in the scaffold, after a longer culture time, such as 4 weeks, the difference became small between the RGDS-modified and unmodified scaffolds.

\subsection{Effect of RGDs immobilization on in vitro mineralization}

Experiments on in vitro mineralization were performed to investigate the tendency of the cultured ROS 


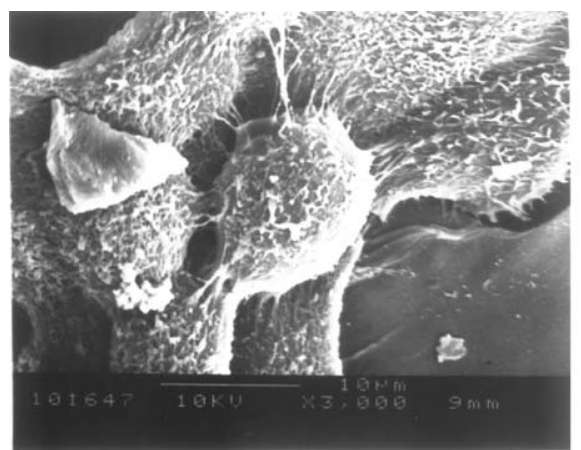

(a)

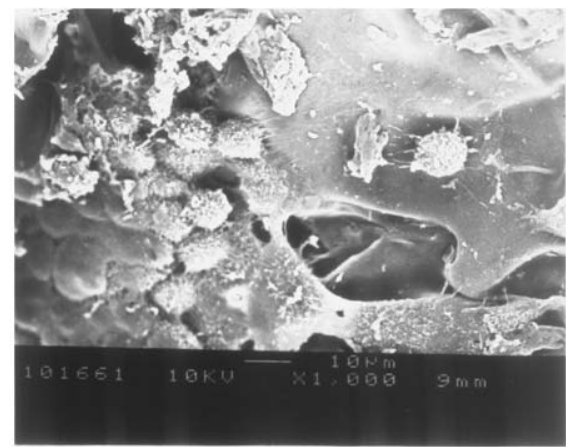

(b)

Fig. 4. Morphological characterization of ROS cells attached to RGDS-immobilized chitosan scaffolds (SEM, (a) $\times 3000$, (b) $\times 1000)$.

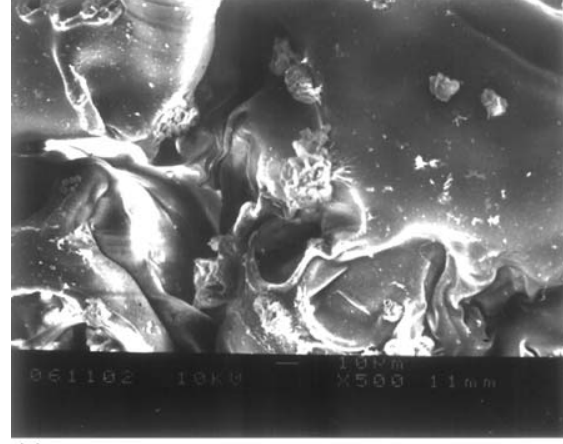

(a)

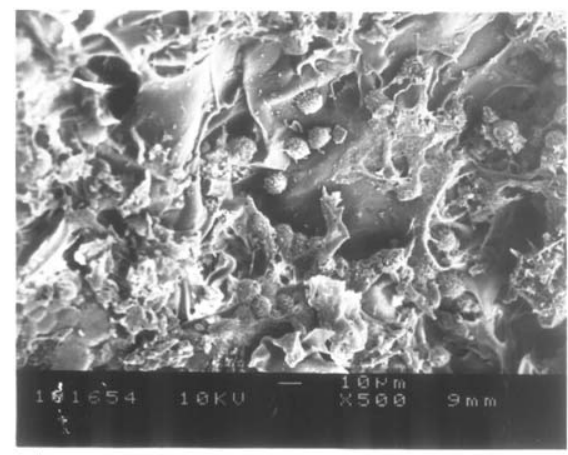

(c)

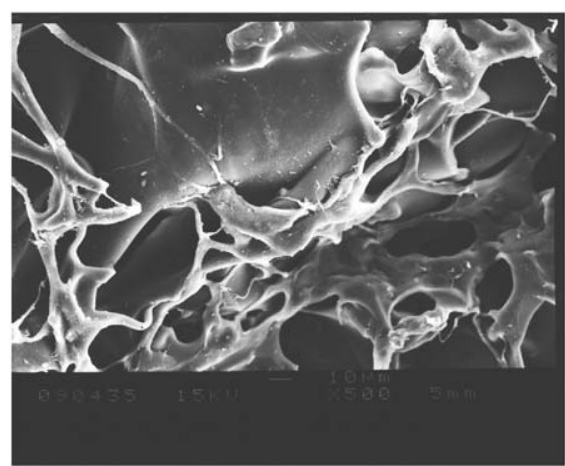

(e)

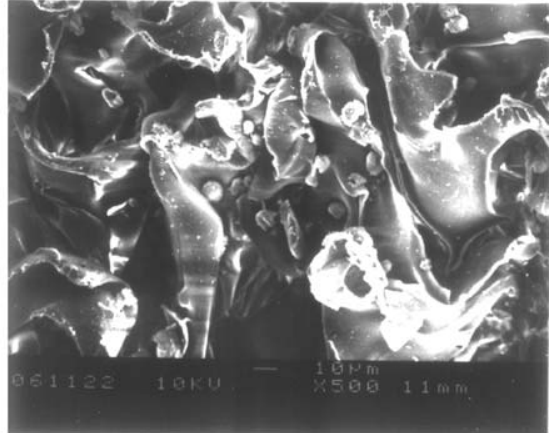

(b)

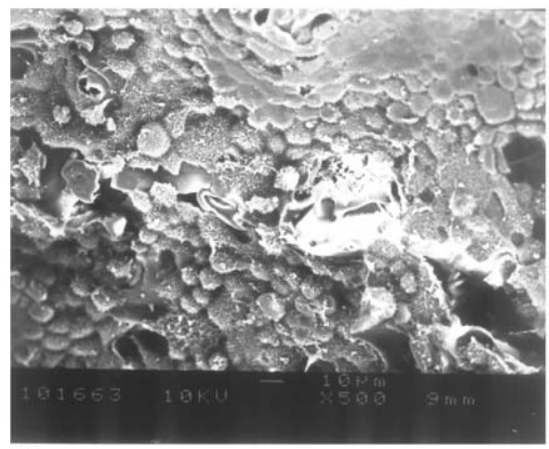

(d)

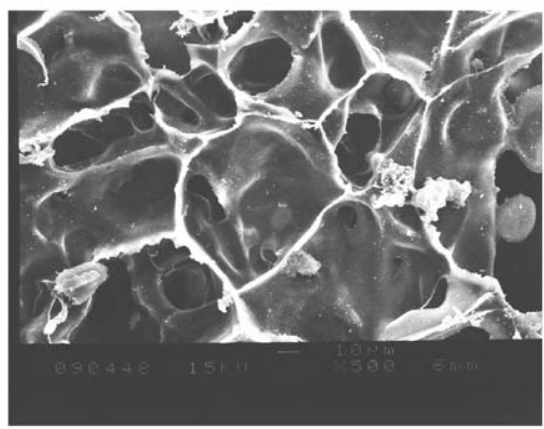

(f)

Fig. 5. Morphological characterization of ROS cells attached to chitosan scaffolds (SEM, $\times 500$ ). (a) and (b): unmodified scaffolds; (c) and (d): RGDS-modified scaffolds; (e) and (f): RGES-modified. (a), (c), and (e): 1 week of cell culture; (b), (d), and (f): 2 weeks of cell culture. 


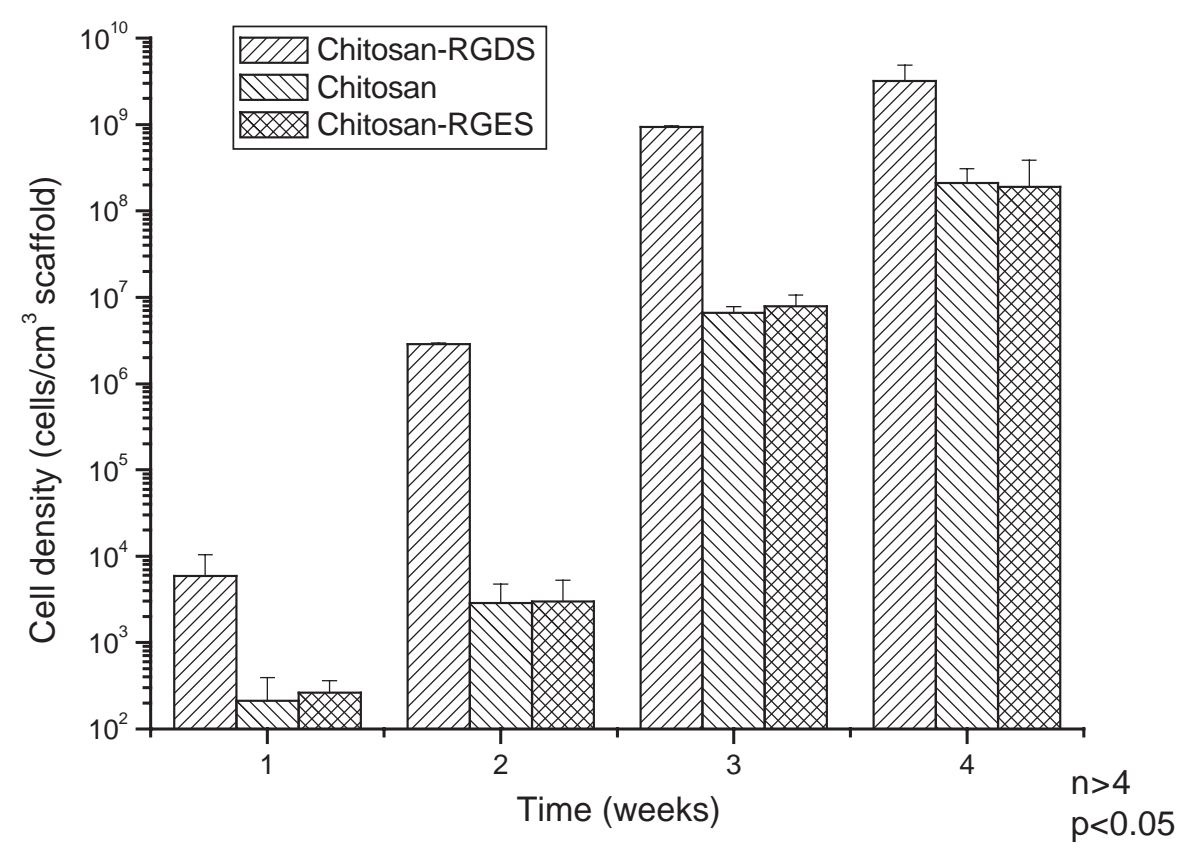

Fig. 6. Densities of ROS cells attached to unmodified, RGDS-modified, and RGES-modified chitosan scaffolds.

cells to form bone-like tissue. After a certain period of culture time, the culture medium was replaced with a mineralization-inducing medium [42] to see if mineralized foci would form from the cultured cells. The ROS cells grew and proliferated in the original culture medium; however, in the mineralizationinducing medium, because of a lack of serum, it was believed that the confluent ROS cells could only mineralize in such an environment without growth and proliferation.

von Kossa staining was performed to investigate mineralization of cultured ROS cells on the scaffold. With von Kossa staining, the calcium in the calcium salt deposits, formed during mineralization, is replaced by silver. The resultant silver salt undergoes reduction to form metallic silver. Thus, dense black spots, markers of the sites of calcium salts, should be observed if the cells are mineralized. In the present study, ROS cells were cultured on RGDS-modified and unmodified scaffolds and were then placed in the mineralization-inducing medium for different time periods. Sign of in vitro mineralization were examined by von Kossa staining, and the results are shown in Fig. 7. The area containing calcium salt (black spots) increased with increasing culture time, indicating that a higher degree of mineralization was obtained with a longer time for in vitro mineralization. Meanwhile, with the same time for culture and mineralization, the scaffold immobilized with RGDS had larger areas of black spots, suggesting that more cells had been mineralized (Fig. 7). Obviously, under the same culture conditions, there were more cells on the RGDS-modified scaffold than on the unmodified scaffold, which tended to have formed bone-like tissue.

The amount of calcium deposited in the cell-mineralized scaffold was further examined using ESCA. With 2 weeks of regular culture and 2 weeks of mineralization, the $\mathrm{Ca} / \mathrm{C}$ ratio was 0.86 for the RGDS-modified, much higher than for the unmodified (0.37) and RGESmodified (0.40) scaffolds. Because only mineralized foci of the extracellular matrix around cells contain calcium, a higher $\mathrm{Ca} / \mathrm{C}$ ratio indicates a higher degree of mineralization. The results are in good agreement with those from von Kossa staining, supporting that a higher degree of mineralization can be obtained with RGDSmodified chitosan scaffolds.

\section{Conclusions}

Chitosan scaffolds were successfully modified with RGDS, and the concentration of the immobilized RGDS in the chitosan was measured to be on the order of $10^{-12} \mathrm{~mol} \mathrm{~cm}^{-2}$. RGDS immobilization enhanced attachment and possible proliferation of ROS cells on chitosan, resulting in higher cell densities attached to the RGDS-modified scaffold than to the unmodified scaffold. It should be noted that only RGDS, but not polypeptides such as RGES, is effective in enhancing cell attachment. It was also found that the greater number of cells in the RGDS-modified scaffold than on the unmodified scaffold tended to enhance the formation 


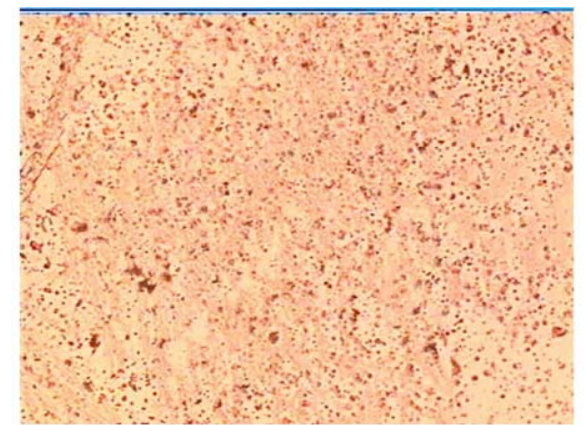

(a)

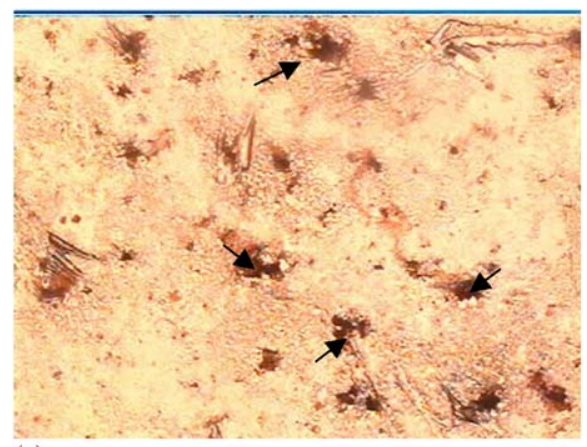

(c)

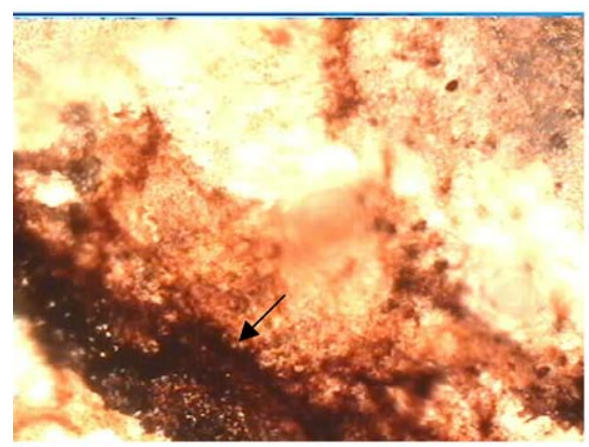

(e)

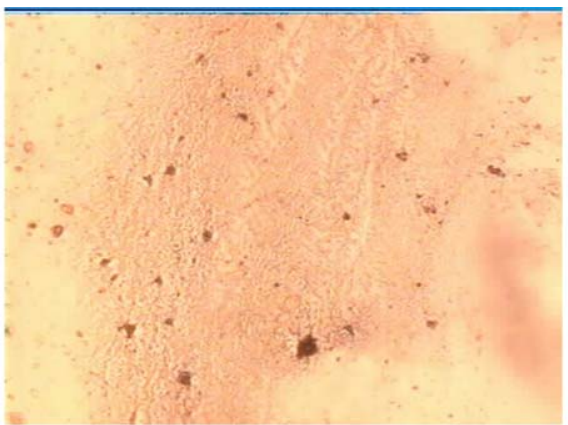

(b)

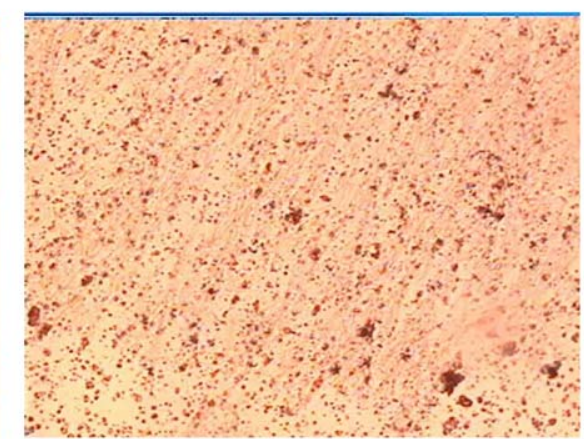

(d)

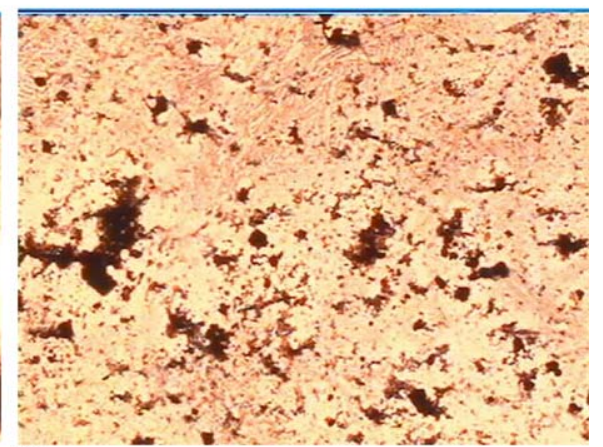

(f)

Fig. 7. Results after von Kossa staining (optical microscopy, $\times 200)$. (a), (b), and (c): ROS cells cultured on RGDS-modified scaffolds; (d), (e), and (f): ROS cells on unmodified scaffolds; (a) and (d): mineralization for 4 days; (b) and (e): mineralization for 1 week; (c), and (f): mineralization for 2 weeks.

of mineralized foci. The results presented herein suggest that immobilization of RGD makes chitosan scaffolds very suitable for the culture of osteoblast-like cells and facilitates its application to tissue engineering of bone tissue.

\section{Acknowledgements}

The authors would like to sincerely thank the financial support from the National Science Council and National Taiwan University Hospital, Taiwan; the help with performing the SEM analysis from Ms. Su-Jen Ji and Prof. Liang-Ping Lin (at the Advanced Instru- ment Center, National Taiwan University, Taipei), and the assistance in performing amino acid analysis from Ms. Jing-Ying Tsai and Prof. Wen-Chang Chang (at the Advanced Instrument Center). Other thanks are given for the aid in carrying out the ESCA analysis from Ms. Chao-Ling Lai and Prof. Chi-Sheng $\mathrm{Wu}$ (of the Department of Chemical Engineering, National Taiwan University, Taipei).

\section{References}

[1] Langer R, Vacanti JP. Tissue engineering. Science 1993;260: $920-6$. 
[2] Hou LT, Tsai AYM, Liu CM, Feng F. Autologous transplantation of gingival fibroblast-like cells and a hydroxylapatite complex graft in the treatment of periodontal osseous defects: cell cultivation and long-term report of cases. Cell Transplant 2003;12:787-97.

[3] Cao Y, Vancanti JP, Paige KT, Upton J, Vacanti CA. Transplantation of chondrocytes utilizing a polymer-cell construct to produce tissue-engineering cartilage in the shape of a human ear. Plast Reconstr Surg 1997;100:297-302.

[4] Freed LE, Marquis JC, Nohria A, Emmanual J, Mikos AC, Langer R. Neocartilage formation in vitro and in vivo using cells cultured on synthetic biodegradable polymers. J Biomed Mater Res 1993;27:11-23.

[5] Mooney DJ, Park S, Kaufmann PM, Sano K, Mcnamara K, Vacanti JP, Langer R. Biodegradable sponges for hepatocyte transplantation. J Biomed Mater Res 1995;29: 959-66.

[6] Mikos AG, Sarakinos G, Lyman MD, Ingber DE, Vacanti JP, Langer R. Prevascularization of porous biodegradable sponges. Biotech Bioeng 1993;42:716-23.

[7] Mooney DJ, Kaufmann PM, Sano K, Mcnamara KM, Vacanti JP, Langer R. Transplantation of hepatocytes using porous biodegradable sponges. Transplant Proc 1994;26:3425-6.

[8] Schugens CH, Grandfils CH, Jerome R, Teyssie P, Delree P, Martin D, Malgrange B, Moonen G. Preparation of a macroporous biodegradable polylactide implant for neuronal transplantation. J Biomed Mater Res 1995;29:1349-62.

[9] Albelda SM, Buck CA. Integrins and other cell adhesion molecules. FASEB J 1990;4:2868-80.

[10] Massia SP, Hubbell JA. Covalent surface immobilization of Arg-Gly Asp and Try-Ile-Gly Ser-Arg containing peptides to obtain well defined cell-adhesive substrates. Anal Biochem 1990;187:292-301.

[11] Massia SP, Hubbell JA. An RGD spacing of $440 \mathrm{~nm}$ is sufficient for integrin $\alpha_{v} \beta_{3}$-mediated fibroblast spreading and $140 \mathrm{~nm}$ for focal contact and stress fiber formation. $J$ Cell Biol 1991;114:1089-100.

[12] Drumheller PD, Elbert DE, Hubbell JA. Multifunctional poly (ethylene glycol) semi-interpenetrating polymer networks as highly selective adhesive substrates for bioadhesive peptide grafting. Biotech Bioeng 1993;43:772-80.

[13] Drumheller PD, Hubbell JA. Polymer networks with grafted cell adhesion peptides for highly biospecific cell adhesive substrate. Analyt Biochem 1994;222:380-8.

[14] Barrera DA, Zyleatra E, Lansbury PT, Langer R. Synthesis and RGD peptide modification of a new biodegradable polymerpoly (lactic acid-co-lysine). J Am Chem Soc 1993;115: $11010-1$

[15] Dee KC, Andersen TT, Bizios R. Osteoblast population migration characteristics on substrates modified with immobilized adhesive peptides. Biomaterials 1999;20:221-7.

[16] Behravesh E, Zygourakis K, Mikos AG. Adhesion and migration of marrow-derived osteoblasts on injectable in situ crosslinkable poly(propylene fumarate-co-ethylene glycol)-based hydrogels with a covalently linked RGDS peptide. J Biomed Mater Res 2003;65A:260-70.

[17] Sagnella SM, Kligman F, Anderson EH, King JE, Murugesan G, Marchant RE, Kottke-Marchant K. Human microvascular endothelial cell growth and migration on biomimetic surfactant polymers. Biomaterials 2004;25:1249-59.

[18] Behravesh E, Mikos AG. Three-dimensional culture of differentiating marrow stromal osteoblasts in biomimetic poly(propylene fumarate-co-ethylene glycol)-based macroporous hydrogels. J Biomed Mater Res 2003;66:698-706.

[19] Hacker M, Tessmar J, Neubauer M, Blaimer A, Blunk T, Gopferich A, Schulz MB. Towards biomimetic scaffolds: anhy- drous scaffold fabrication from biodegradable amine-reactive diblock copolymers. Biomaterials 2003;24:4459-73.

[20] Chung TW, Lu YF, Wang HY, Chen WP, Wang SS, Lin YS, Chu $\mathrm{SH}$. Growth of human endothelial cells on different concentrations of Gly-Arg-Gly-Asp grafted chitosan surface. Artif Organs 2003;27:155-61.

[21] $\mathrm{Hu} \mathrm{Y,} \mathrm{Winn} \mathrm{SR,} \mathrm{Krajbicj} \mathrm{I,} \mathrm{Hollinger} \mathrm{JO.} \mathrm{Porous} \mathrm{polymer}$ scaffolds surface-modified with arginine-glycine-aspartic acid enhance bone cell attachment and differentiation in vitro. J Biomed Mater Res 2003;64A:583-90.

[22] Xu HHK, Quinn JB, Takagi S, Chow LC. Synergistic reinforcement of in situ hardening calcium phosphate composite scaffold for bone tissue engineering, Biomaterials 2004;25: 1029-37.

[23] Yin YJ, Ye F, Cui JF, Zhang FJ, Li XL, Yao KD. Preparation and characterization of macroporous chitosan-gelatin betatricalcium phosphate composite scaffolds for bone tissue engineering. J Biomed Mater Res A 2003;67:844-55.

[24] Hu QL, Li BQ, Wang M, Shen JC. Preparation and characterization of biodegradable chitosan/hydroxyapatite nanocomposite rods via in situ hybridization: a potential material as internal fixation of bone fracture. Biomaterials 2004;25:779-85.

[25] Chung TW, Lu YF, Wang SS, Lin YS, Chu SH. Growth of human endothelial cells on photochemically grafted Gly-ArgGly-Asp (GRGD) chitosans. Biomaterials 2002;23:4803-9.

[26] Burdick JA, Anseth KS. Photoencapsulation of osteoblasts in injectable RGD-modified PEG hydrogels for bone tissue engineering. Biomaterials 2002;23:4315-23.

[27] Henke L, Piunno PAE, McClure AC, Krull UJ. Covalent immobilization of single-stranded DNA onto optical fibers using various linkers, Analyt. Chim Acta 1997;344:201-13.

[28] Steffens GCM, Buse LNG, Thissen BH, Höcker H, Klee D. High density binding of proteins peptides to poly (D,L-lactide) grafted with polyacrylic acid. Biomaterials 2002;23:3523-31.

[29] Hou LT, Liu CM, Lei JY, Wong MY, Chen JK. Biological effects of cementum and bone extracts on human periodontal fibroblasts, J. Periodontol 2000;71:1100-9.

[30] Schenk RK, Olah AJ, Herrmann W. Preparation of calcified tissues for light microscopy. In: Dickson GR editor. Methods of calcified tissue preparation. New York: Elsevier; 1984. p. 1.

[31] Damink LHHO, Dijkstra PJ, Luyn MJAV, Wachem PBV, Nieuwenhuis P, Feijen J. Cross-linking of dermal sheep collagen using a water-soluble carbodiimide. Biomaterials 1996;17: 765-73.

[32] Tomihata K, Ikada Y. Cross-linking of hyaluronic acid with water-soluble carbodiimide. J Biomed Mater Res 1997;37: 243-51.

[33] Oguntimein GB, Reilly PJ. Purification and immobilization of Aspergillus niger b-xylosidase. Biotechnol Bioeng 1980;12: 1127-42.

[34] Chan ECY, Ho PC. Preparation and characterization of immunogens for antibody production against methanephrine and normetanephrine. J Immunol Methods 2002;266: 143-54.

[35] Quirk RA, Chan WC, Davies MC, Tendler SJB, Shakesheff KM. Poly(L-lysine)-GRGDS as a biomimetic surface modifier for poly(lactic acid). Biomaterials 2001;22:865-72.

[36] Kouvroukoglou S, Dee KC, Bizios R, McIntire LV, Zygourakis $\mathrm{K}$. Endothelial cell migration on surfaces modified with immobilized adhesive peptides. Biomaterials 2000;21:1725-33.

[37] Wissink MJB, Beernink R, Poot AA, Engbers GHM, Beugeling T, Aken WGV, Feijen AJ. Relational between cell density and the secretion of von Willeberand factor and prostacyclin by human umbilical vein endothelial cells. Biomaterials 2001;22:2283-90.

[38] Tedder JM, Nechvatal A, Murray AW. Basic organic chemistry, 1st ed. New York: Wiley; 1972 (Chapter 6). 
[39] Socrates G. Infrared characteristic group frequencies tables and charts, 2nd ed. New York: Wiley; 1998. pp. 74-79.

[40] Drumheller PD, Elbert DE, Hubbell JA. Multifunctional poly (ethylene glycol) semi-interpenetrating polymer networks as highly selective substrates for bioadhesive peptide grafting. Biotech Bioeng 1993;43:772-80.
[41] Drumheller PD, Hubbell JA. Polymer networks with grafted cell adhesion peptides for highly biospecific cell adhesive substrate. Analyt Biochem 1994;222:380-8.

[42] Hou LT, Liu CM, Lei JY, Wong MY, Chen JK. Biological effects of cementum and bone extracts on human periodontal fibroblasts. J Peridontol 2000;71:1100-9. 